\title{
Characterization of Fluoride Phosphors for Diode Pumped Solid-State Lighting Applications
}

\author{
Bommareddi Rami Reddy*, Kristopher Liggins, Vernessa M. Edwards \\ Department of Physics, Alabama A \& M University, Normal, AL, USA \\ Email: ^rami.bommareddi@aamu.edu
}

How to cite this paper: Reddy, B.R., Liggins, K. and Edwards, V.M. (2018) Characterization of Fluoride Phosphors for Diode Pumped Solid-State Lighting Applications. Optics and Photonics Journal, 8, 288-300. https://doi.org/10.4236/opj.2018.88024

Received: July 13, 2018

Accepted: August 24, 2018

Published: August 27, 2018

Copyright $\odot 2018$ by authors and Scientific Research Publishing Inc. This work is licensed under the Creative Commons Attribution International License (CC BY 4.0).

http://creativecommons.org/licenses/by/4.0/

\section{c) (i) Open Access}

\begin{abstract}
Phosphor coated diodes are critical to the lighting industry. Rare-earth doped fluoride phosphors are characterized in this work. Spectroscopy and lifetime measurements of $\mathrm{CaF}_{2}: \mathrm{Dy}^{3+}, \mathrm{LaF}_{3}: \mathrm{Eu}^{3+}$ and $\mathrm{Tb}^{3+}$-doped $\mathrm{LaF}_{3}$ and $\mathrm{CaF}_{2}$ crystals were performed by irradiating the samples with 405 and $375 \mathrm{~nm}$ diode lasers. Chromaticity diagrams are developed from spectral measurements. $\mathrm{Dy}^{3+}$-doped $\mathrm{CaF}_{2}$ revealed bright white light emission having peaks at 492, 570 and $654 \mathrm{~nm}$. The measured color coordinates are $\mathrm{x}=0.322$ and $\mathrm{y}=0.340$ for $\mathrm{Dy}^{3+}$-doped $\mathrm{CaF}_{2}$ and these values are close to those of sunlight and the coordinated color temperature is $6147 \mathrm{~K}$, under $405 \mathrm{~m}$ laser excitation. $\mathrm{Eu}^{3+}$-doped $\mathrm{LaF}_{3}$ revealed twenty emission peaks in the visible wavelength region. The color coordinates measured for $\mathrm{LaF}_{3}: \mathrm{Eu}^{3+}$ are $\mathrm{x}=0.283$ and $\mathrm{y}=$ 0.293 under $405 \mathrm{~nm}$ diode laser excitation and the color temperature is 9557 $\mathrm{K} . \mathrm{Eu}^{3+}$-doped $\mathrm{LaF}_{3}$ provides cool white-light, under $405 \mathrm{~nm}$ diode laser excitation. $\mathrm{Tb}^{3+}$-doped fluoride crystals revealed bright white light under low power diode laser excitation. The measured color coordinates for $\mathrm{Tb}^{3+}$-doped $\mathrm{CaF}_{2}$ are $\mathrm{x}=0.329$ and $\mathrm{y}=0.558$ and the color temperature is $7713 \mathrm{~K}$. The color coordinates for $\mathrm{LaF}_{3}: \mathrm{Tb}^{3+}$ are $\mathrm{x}=0.342$ and $\mathrm{y}=0.365$ and the coordinated color temperature is $5370 \mathrm{~K}$. These values are close to those of sunlight.
\end{abstract}

\section{Keywords}

Rare-Earth Spectroscopy, White-Light Emission, Color Coordinates, Coordinated Color Temperature, Fluoride Materials, Laser Induced Fluorescence, Europium, Terbium, Dysprosium Ions

\section{Introduction}

About 20 percent of the electricity supplied to homes is used in lighting. One of 
the current research areas is the design of all solid-state white-light emitters which are energy efficient, robust and free from pollution [1]. There is an ongoing global effort to design efficient solid-state white-light sources. For this purpose, both organic and inorganic materials are being investigated which emit white-light under electrical pumping [2] [3] [4]. In the category of inorganic materials, semiconductor diodes, quantum dots and diode pumped phosphor materials are under consideration. One class of materials that emit white light is diode pumped phosphors which are embedded with inorganic ions [5]-[11]. Light emitting diodes (LED) consume less energy, do not pollute the environment and last much longer than their counterparts. Some of the rare-earth ions possess numerous energy levels and emit in the visible and infrared wavelength regions. Depending on the energy level structure, a rare-earth ion may absorb certain discrete lasers wavelengths. Because of these characteristic spectral features, materials embedded with single, double or triple dopants, emit different colors. White-light sensation occurs whenever the three primary colors are mixed in various combinations. Accordingly, any material that emits red, green and blue light in appropriate combinations generates white light. In this paper, rare-earth doped fluoride phosphors that produce white light under diode pumping are discussed. Materials used for solid-state lighting are characterized by measuring the color rendering index or the color coordinates. The ability of a light source to reveal the colors of different objects is expressed in terms of color rendering index. Luminous efficacy, expressed in Lumens/Watt, is the radiant power, in the visible part of the spectrum. Higher index values are preferred in lighting industries. Another way of measuring the source performance is to measure color coordinates and coordinated color temperature (CCT). CCT is a measure of the source color appearance. In this manuscript, we evaluated the materials by measuring the color coordinates and CCT.

Rare-earth ion doped materials were investigated because of their applications in the laser development, luminescent devices, optical refrigeration, optical memories, temperature measurement and others [12] [13] [14] [15] [16]. $\mathrm{LaF}_{3}$ and $\mathrm{CaF}_{2}$ possess high melting points $1550^{\circ} \mathrm{C}$ and $1450^{\circ} \mathrm{C}$ respectively. These crystals have wide transmission range covering the visible and infrared regions. The space group of $\mathrm{LaF}_{3}$ is trigonal and the dopant ions occupy the isovalent $\mathrm{La}$ sites [17]. Spectroscopy and X-ray diffraction studies revealed a single type of site, $\mathrm{C}_{2}$ for the dopant ions. $\mathrm{CaF}_{2}$ is a cubic material and the trivalent dopant ions occupy bivalent cationic sites. Consequently, the dopant ions occupy multiple sites in the $\mathrm{CaF}_{2}$ host [18]. Conventional spectroscopy work revealed five types of major sites for the dopant ion whereas a high resolution spectroscopy work revealed numerous sites for the dopant ion. The crystal field splittings are smaller than the spin-orbit coupling. The centers of gravity of the multiplets do not change much from one host to another host material. The number of crystal field components of a multiplet depends on the site symmetry of the rare-earth ion. $\mathrm{Eu}^{3+}$ and $\mathrm{Dy}^{3+}$-doped materials were not used in the laser development. 
However, $\mathrm{Eu}^{3+}$-doped materials were extensively investigated because their possible applications in optical hole burning memory devices [16]. Published literature on $\mathrm{Dy}^{3+}$-doped materials is far less than that for $\mathrm{Er}^{3+}$-doped materials because the latter is used in the laser development. Moreover, at higher doping levels concentration quenching dominates in $\mathrm{Dy}^{3+}$-doped materials. Lately, rare-earth doped materials are being investigated for possible applications in solid-state lighting [19]-[24]. Rare-earth doped $\mathrm{LaF}_{3}$ and $\mathrm{CaF}_{2}$ are relatively stable when compared to other materials, because of their high melting points. Crystal growth of $\mathrm{CaF}_{2}$ is a mature technology and large windows are grown for infrared applications. In the current study the suitability of these materials for solid-state lighting applications is discussed. In a solid, excited rare-earth ions relax radiatively and non-radiatively [25]. The former depends on the transition probabilities which are calculated using Judd-Ofelt intensity parameters which, in turn, are derived from the absorption spectrum. The radiative probabilities are independent of temperature. The non-radiative relaxation is temperature dependent and its value depends on the energy gap between the levels and the cut-off phonon frequency [26]. The cut-off phonon frequency depends on the reduced mass of the molecule and force constants. The phonon structure is revealed by Raman and infrared spectral measurements. The cut-off phonon frequency of $\mathrm{LaF}_{3}$ and $\mathrm{CaF}_{2}$ crystals are 360 and $380 \mathrm{~cm}^{-1}$ respectively.

\section{Experimental Details}

The crystals used for this investigation were obtained from Optovac, Inc. The crystals are of the size $8 \times 6 \times 4 \mathrm{~mm}^{3}$ and were polished for optical studies. Optical absorption spectroscopy measurements were performed by a Cary $3 \mathrm{E}$ spectrophotometer. The fluorescence spectroscopy measurements were performed using a Stellarnet spectrometer. Luminescence was generated from the samples by exposing them to Coherent OBIS 375 or $405 \mathrm{~nm}$ diode lasers. For lifetime measurements the laser beams were chopped at $100 \mathrm{~Hz}$ by a mechanical chopper to generate laser pulses. The luminescence was acquired by a fiber bundle whose other end was connected to an Acton Research Corporation, Spectra Pro 500 spectrometer (Figure 1). The spectrometer output was detected by a Hamamatsu R928 photomultiplier tube (PMT). The PMT output was amplified and then acquired by a Stanford Research Corporation, SRC 430 multichannel scaler. The resulting decay signals were fitted to single exponentials to derive the lifetimes of the excited levels. For the measurement of color coordinates and CCT the spectra were acquired by a Stellar Net spectrometer.

\section{Results and Discussion}

\section{1. $\mathrm{CaF} 2: \mathrm{Dy}^{3+}(0.17 \%)$}

A partial energy level diagram was generated from the absorption spectral measurements (Figure 2). The energy levels are identified by comparing the spectral 


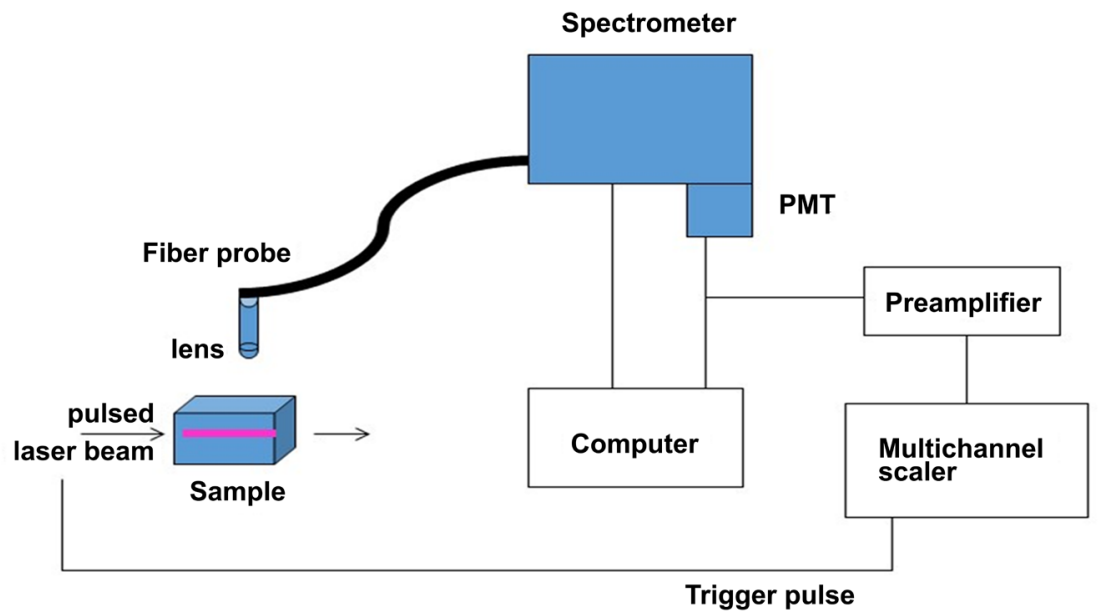

Figure 1. A block diagram of the experimental setup used for lifetime measurement.

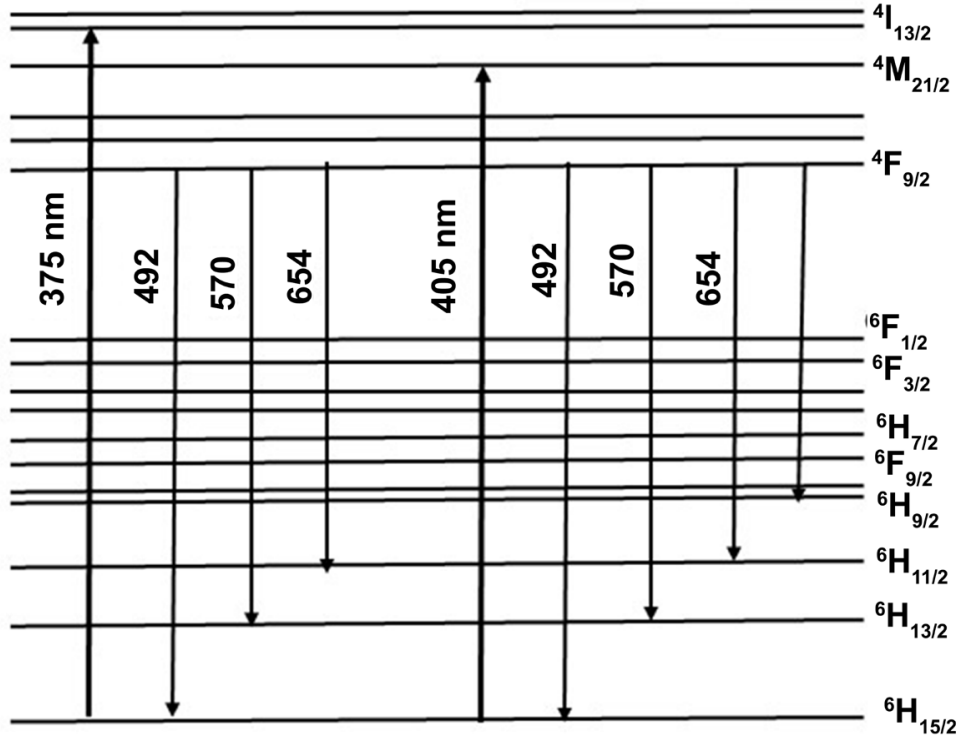

Figure 2. Partial energy level diagram of $\mathrm{Dy}^{3+}$ ion depicting emission transitions, under 375 and $405 \mathrm{~nm}$ diode laser excitations.

wavelengths with those of literature values. The $405 \mathrm{~nm}$ diode laser resonantly excites the ${ }^{4} \mathrm{M}_{21 / 2}$ level, whereas the $375 \mathrm{~nm}$ laser resonantly excites ${ }^{4} \mathrm{I}_{13 / 2}$ level. Excited ions relax non-radiatively in cascade to ${ }^{4} \mathrm{~F}_{9 / 2}$. The energy gap between ${ }^{4} \mathrm{~F}_{9 / 2}$ and its lower level is very large and hence ${ }^{4} \mathrm{~F}_{9 / 2}$ relaxes radiatively to the lower levels with $100 \%$ quantum efficiency, in the absence of concentration quenching effects. The fluorescence spectrum observed under a $375 \mathrm{~nm}$ diode laser is shown in Figure 3 and the sample color is shown in the inset. Figure 3 reveals emission peaks at $492\left({ }^{4} \mathrm{~F}_{9 / 2} \rightarrow{ }^{6} \mathrm{H}_{15 / 2}\right), 570\left({ }^{4} \mathrm{~F}_{9 / 2} \rightarrow{ }^{6} \mathrm{H}_{13 / 2}\right)$ and $654 \mathrm{~nm}$ $\left({ }^{4} \mathrm{~F}_{9 / 2} \rightarrow{ }^{6} \mathrm{H}_{11 / 2}\right)$; the spectral identifications are given in parentheses. The fluorescence contains blue, green and red colors and hence the sample color is white along the beam path. The emission spectrum is identical even for $405 \mathrm{~nm}$ excitation. The measured lifetime of ${ }^{4} \mathrm{~F}_{9 / 2}$ level is $1.3 \pm 0.1 \mathrm{~ms}$. Each emission peak is a 


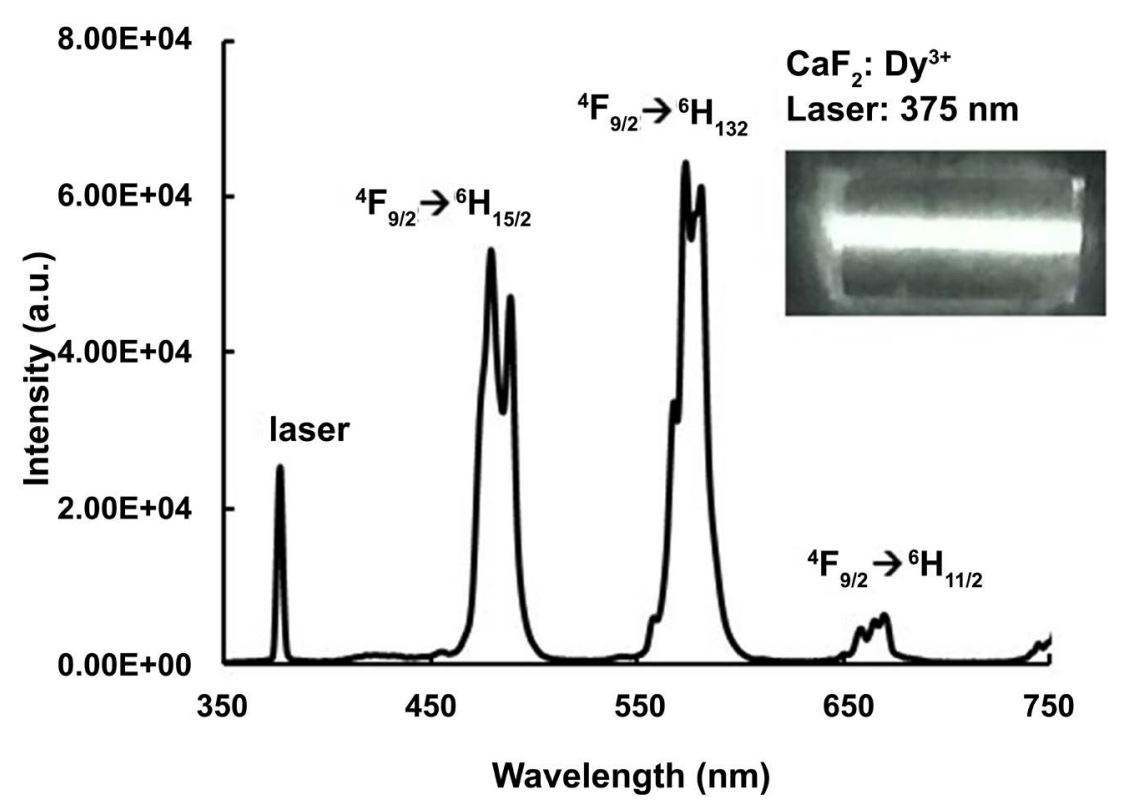

Figure 3. Emission spectrum of $\mathrm{CaF}_{2}: \mathrm{Dy}^{3+}$ observed under $375 \mathrm{~nm}$ laser excitation. Inset in the figure is the sample photograph depicting the emission color.

convolution of spectral overlap emitted by different sites. Hence the uncertainty in the measured lifetime is large. It is customary to compare the sample emission color with that of sunlight. The color is characterized by developing a chromaticity diagram to estimate color coordinates and coordinated color temperature (CCT). The color coordinates of $\mathrm{CaF}_{2}: \mathrm{Dy}^{3+}$ are $\mathrm{x}=0.322$ and $\mathrm{y}=0.340$ and the color temperature is $6147 \mathrm{~K}$, under $405 \mathrm{~nm}$ laser excitation, which are close enough to those of sunlight values; $x=0.33$ and $y=0.33$. The color coordinates are $\mathrm{x}=0.338$ and $\mathrm{y}=0.36$ under $375 \mathrm{~nm}$ laser excitation, and the CCT is $5474 \mathrm{~K}$ (Figure 4). The pink curve in the middle of the figure represents the path of the color of a blackbody as a function of its temperature, also called Planckian locus. The color coordinates of sunlight, $\mathrm{x}=0.33, \mathrm{y}=0.33$ are located at the crossing of the two straight lines, called, achromatic point. Inset in Figure 3 reveals the sample emission color, observed under $375 \mathrm{~nm}$ laser excitation. Though fluorescence is generated from the same upper level, ${ }^{4} \mathrm{~F}_{9 / 2}$, for both 375 and $405 \mathrm{~nm}$ laser excitations, the color coordinates change slightly when the sample is excited with different diodes. Each diode laser may excite one or more sites, depending on the laser wavelength. The energy level positions and transition probabilities change from one site to another. Hence, the color coordinates and color temperature differ slightly under different laser excitations.

\section{2. $\mathrm{LaF}_{3}: \mathrm{Eu}^{3+}(0.3 \%)$}

A partial energy level diagram of $\mathrm{Eu}^{3+}$ is shown in Figure 5. $\mathrm{Eu}^{3+}$ ions occupy a single type of site in this material. 405 and $375 \mathrm{~nm}$ lasers resonantly excite ${ }^{5} \mathrm{D}_{3}$ and ${ }^{5} \mathrm{~L}_{7}$ levels, respectively. Excited ions relax radiatively and non-radiatively in cascade to the lower levels. Transition probabilities predict radiative transitions 


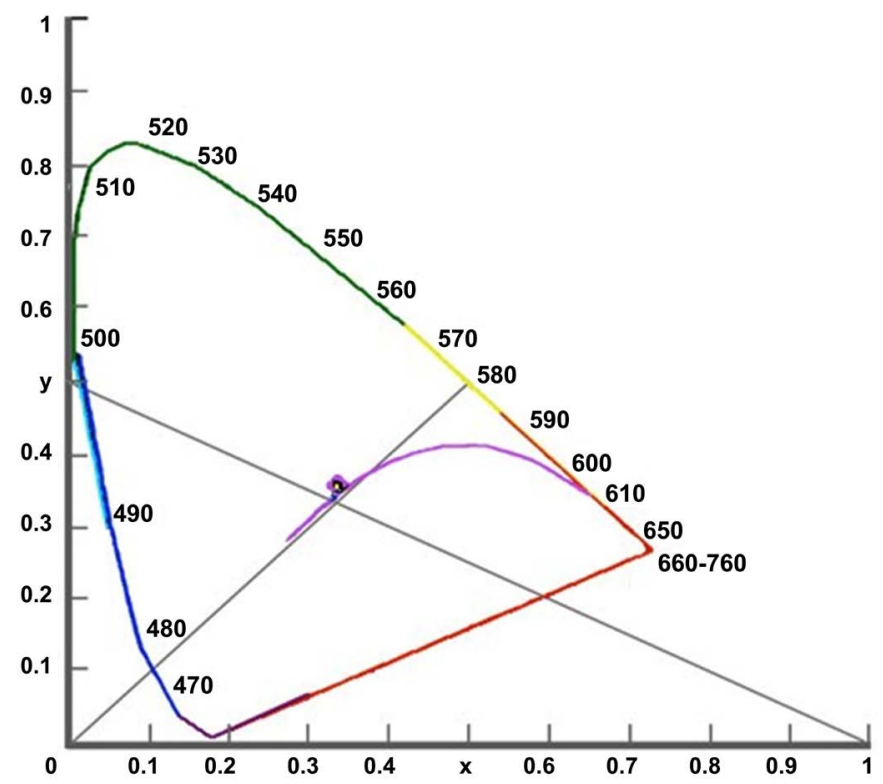

Figure 4. Chromaticity diagram of $\mathrm{CaF}_{2}: \mathrm{Dy}^{3+}$ measured with $375 \mathrm{~nm}$ diode laser excitation. The color coordinates are $\mathrm{x}=0.338$ and $\mathrm{y}=0.36$ and CCT is $5474 \mathrm{~K}$.

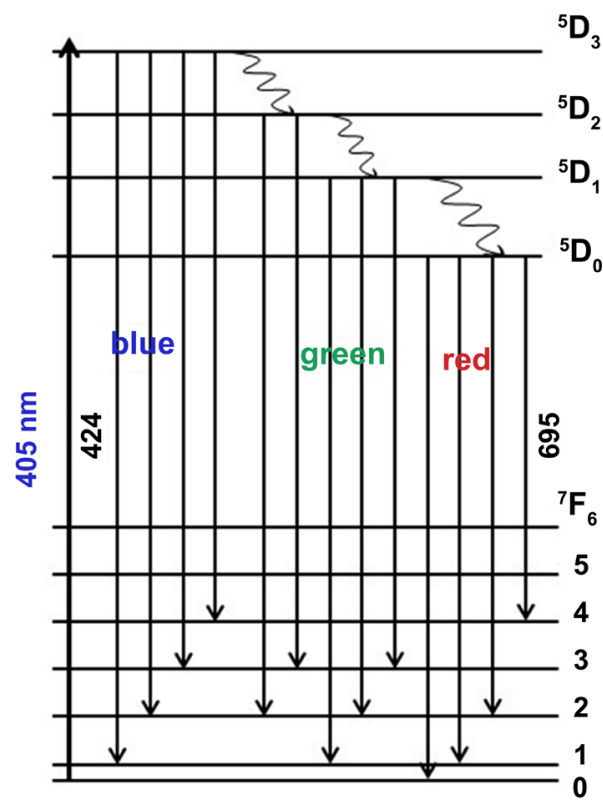

Figure 5. Partial energy level diagram of $\mathrm{LaF}_{3}: \mathrm{Eu}^{3+}$ depicting absorption and emission transitions under diode laser excitation.

to several lower multiplets from each excited state. As a result, radiative relaxation occurs from ${ }^{5} \mathrm{D}_{3},{ }^{5} \mathrm{D}_{2},{ }^{5} \mathrm{D}_{1}$ and ${ }^{5} \mathrm{D}_{0}$ multiplets to several ground state manifolds, ${ }^{7} F_{J}(J=0$ to 6$)$. Fluorescence spectrum shown in Figure 6 reveals numerous transitions from 400 to $700 \mathrm{~nm}$. Hence, the sample emission is white as exhibited by the photograph (inset in Figure 6). Spectral identifications are shown on the same figure. Lifetime measurements confirm the spectral identifications. The lifetimes of ${ }^{5} \mathrm{D}_{J}$ manifolds $(J=0,1,2$ and 3$)$ are in the millisecond range. 


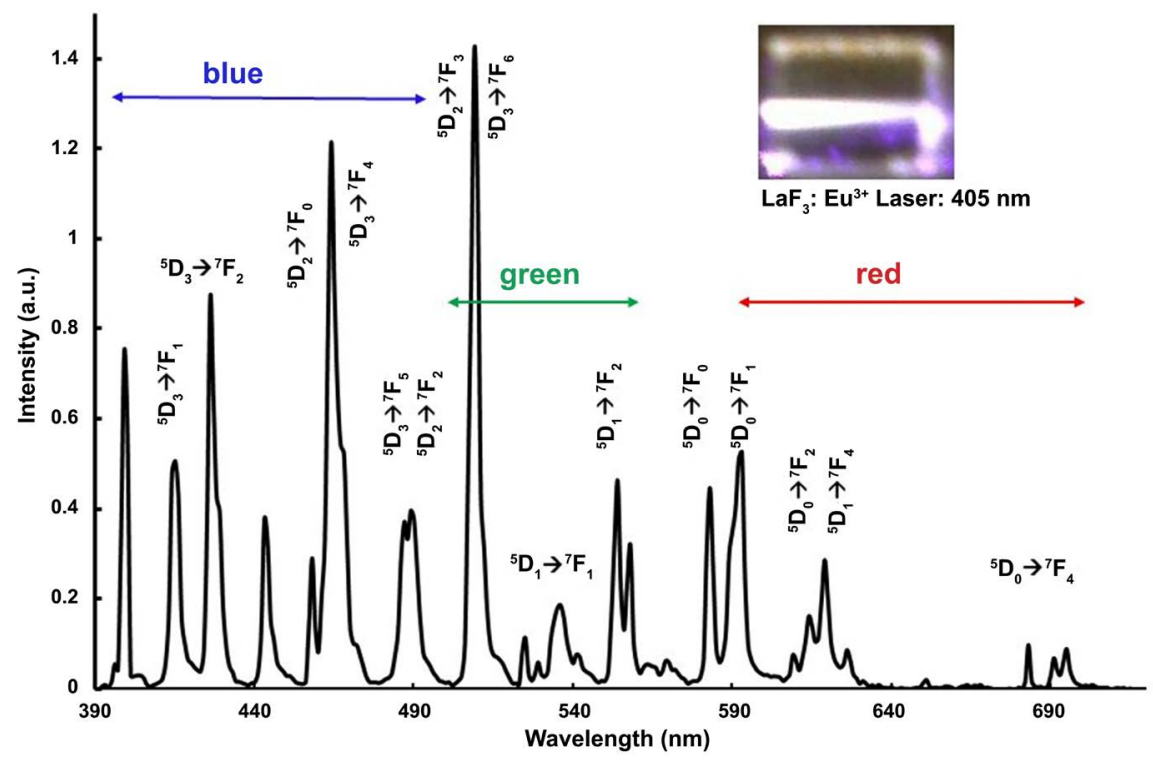

Figure 6. Fluorescenece spectrum of $\mathrm{LaF}_{3}: \mathrm{Eu}^{3+}$ observed with $405 \mathrm{~nm}$ diode laser excitation. The inset in the figure is a photograpgh of the sample, which reveals white emission color.

Chromaticity diagrams are developed for this material from the emission measurements under 375 and $405 \mathrm{~nm}$ laser excitations. The color coordinates are $\mathrm{x}=$ 0.283 and $y=0.293$ under $405 \mathrm{~nm}$ laser excitation and the coordinated color temperature is $9557 \mathrm{~K}$ (Figure 7). This indicates that the emission color of this material is cool white. Under $375 \mathrm{~nm}$ laser excitation the measured color coordinates are $\mathrm{x}=0.273$ and $\mathrm{y}=0.282$ and the color temperature is $11,648 \mathrm{~K}$ (figure not shown). The sample absorption is relatively stronger at $375 \mathrm{~nm}$. The intensities of the spectral components, in the blue wavelength region $400-450 \mathrm{~nm}$, increase for $375 \mathrm{~nm}$ laser excitation when compared to those observed under $405 \mathrm{~nm}$ excitation. Hence, the color temperature increased and the color coordinates shifted more towards cool white.

\section{3. $\mathrm{Tb}^{3+}-$ Doped $\mathrm{CaF}_{2}$ and $\mathrm{LaF}_{3}$}

The absorption spectrum of $\mathrm{CaF}_{2}: \mathrm{Tb}^{3+}(0.1 \%)$ is shown in Figure 8. It revealed peaks at $257\left({ }^{5} \mathrm{~K}_{9}\right), 274\left({ }^{5} \mathrm{~F}_{4}\right), 286\left({ }^{5} \mathrm{~F}_{5}\right), 295\left({ }^{5} \mathrm{H}_{5}\right), 303\left({ }^{5} \mathrm{H}_{6}\right), 320\left({ }^{5} \mathrm{D}_{0}\right), 329\left({ }^{5} \mathrm{D}_{1}\right)$, $343\left({ }^{5} \mathrm{G}_{3}\right), 352\left({ }^{5} \mathrm{G}_{4}\right), 367\left({ }^{5} \mathrm{~L}_{10}\right), 380\left({ }^{5} \mathrm{D}_{3}\right)$, and $488 \mathrm{~nm}\left({ }^{5} \mathrm{D}_{4}\right)$. The symbols in the parentheses represent the corresponding spectral terms of the excited energy states. The absorption spectrum does not reveal any peak in the vicinity of 405 $\mathrm{nm}$. Accordingly, the material did not reveal any fluorescence from ${ }^{5} \mathrm{D}_{\mathrm{J}}(\mathrm{J}=3,4)$ levels under $405 \mathrm{~nm}$ excitation. However, the sample emitted bright white light under $375 \mathrm{~nm}$ laser excitation (Figure 9). When the fluorescence was analyzed with a spectrometer it revealed a weaker peak at $426 \mathrm{~nm}$ and more intense peaks in the blue, green, orange and red regions, respectively at $492\left({ }^{5} \mathrm{D}_{4} \rightarrow{ }^{7} \mathrm{~F}_{6}\right), 549$ $\left({ }^{5} \mathrm{D}_{4} \rightarrow{ }^{7} \mathrm{~F}_{5}\right), 580\left({ }^{5} \mathrm{D}_{4} \rightarrow{ }^{7} \mathrm{~F}_{4}\right)$ and $631 \mathrm{~nm}\left({ }^{5} \mathrm{D}_{4} \rightarrow{ }^{7} \mathrm{~F}_{3}\right)$. Because the emission spectrum is a superposition of blue, green and red colors, sample emission appears to 


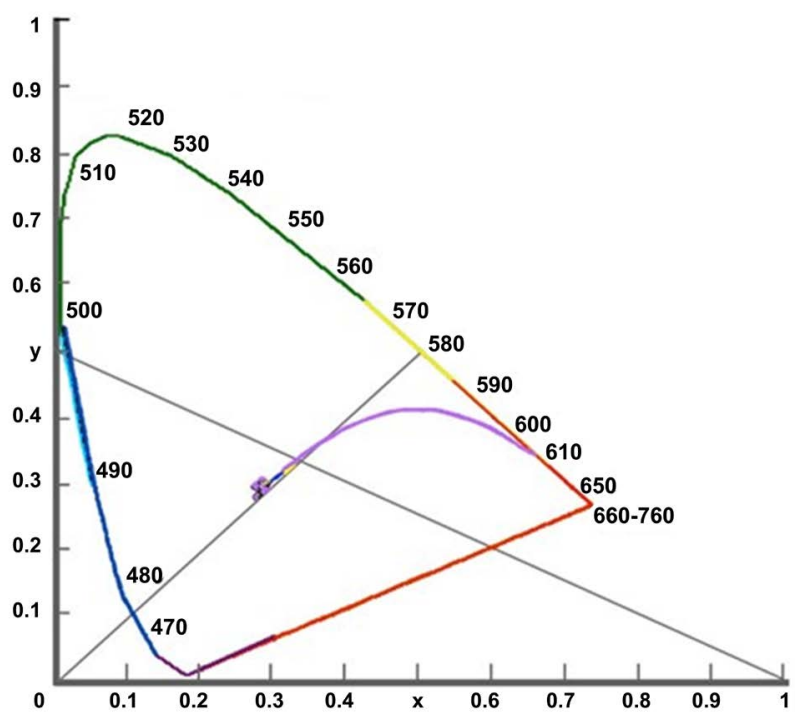

Figure 7. Chromaticity diagram of $\mathrm{LaF}_{3}: \mathrm{Eu}^{3+}$ measured with $405 \mathrm{~nm}$ diode laser excitation. Color coordinates are $\mathrm{x}=0.273$ and $\mathrm{y}=0.282$ and CCT is $9557 \mathrm{~K}$.

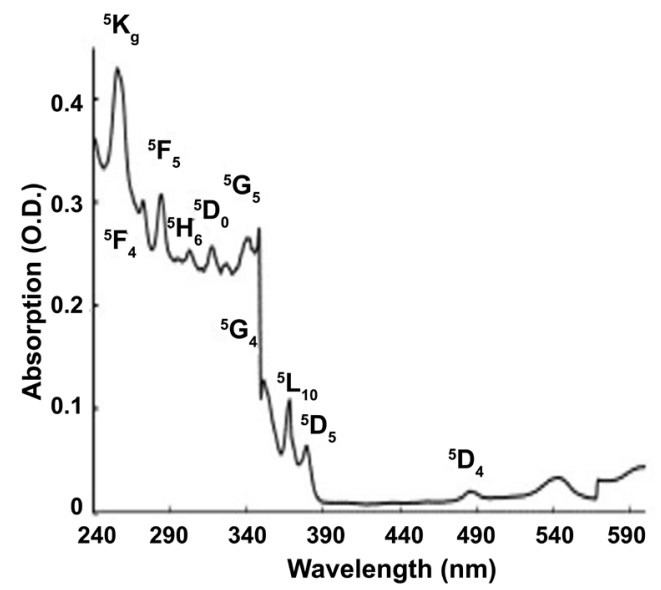

Figure 8. Absorption spectrum of $\mathrm{Tb}^{3+}$-doped $\mathrm{CaF}_{2}$.

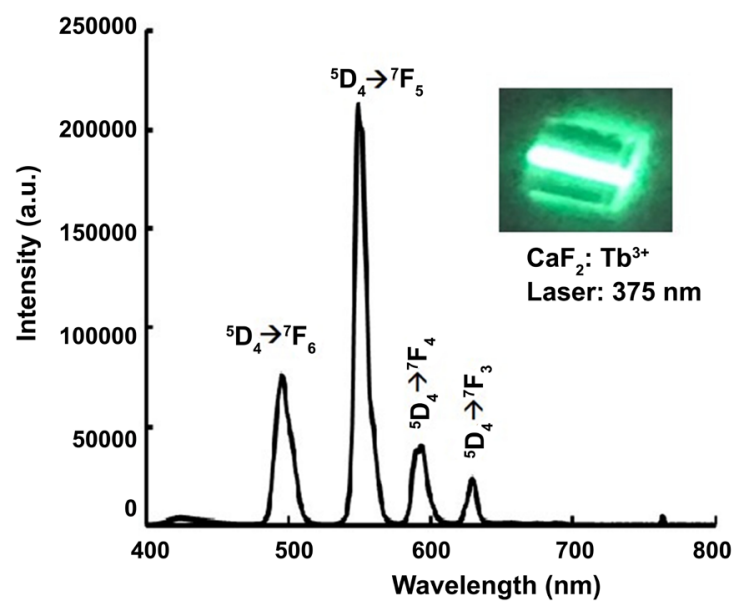

Figure 9. Fluorescence spectrum of $\mathrm{CaF}_{2}: \mathrm{Tb}^{3+}$ generated with $375 \mathrm{~nm}$ laser excitation. Inset is the sample photograph under laser illumination. 
be white as shown in the inset of Figure 9. The emission intensity of the green peak is relatively more intense. Moreover, the responsivity of human eye is maximum for the green color emission. Hence, the sample scattering is greenish in appearance. The $375 \mathrm{~nm}$ laser $\left(26,666 \mathrm{~cm}^{-1}\right)$ resonantly excites ${ }^{5} \mathrm{G}_{6}$ level $\left(26,547 \mathrm{~cm}^{-1}\right)$ as shown in Figure 10, which relaxes in cascade to the lower levels causing ${ }^{5} \mathrm{D}_{4}$ levels to emit. When lifetimes were measured by monitoring different emission wavelengths they all revealed the same value $4.4 \pm 0.3 \mathrm{~ms}$, which confirms that all these wavelengths arise from the same upper level, ${ }^{5} \mathrm{D}_{4}$. The uncertainty in lifetime is large when monitored at different emission wavelengths, because of the spectral overlap arising from different sites.

$\mathrm{Tb}^{3+}$-doped materials revealed emission from ${ }^{5} \mathrm{D}_{3}$ level under $\mathrm{Ar}^{+}$laser excitation [27] [28], due to stepwise two-photon excitation mechanism. However, in $\mathrm{Tb}^{3+}$-doped $\mathrm{CaF}_{2}$, no emission was detected from ${ }^{5} \mathrm{D}_{3}$ level under $375 \mathrm{~nm}$ laser excitation. When the $375 \mathrm{~nm}$ laser beam passed through $\mathrm{LaF}_{3}: \mathrm{Tb}^{3+}(1 \%)$ the sample glow was much brighter. The laser light was absorbed by the sample within a millimeter length of the sample. However, the emission spectrum revealed numerous peaks (Figure 11). An analysis of the energy levels [12]-[17] indicates that the $375 \mathrm{~nm}$ laser light resonantly excites one of the crystal fields components of $\mathrm{Tb}^{3+}$ in $\mathrm{LaF}_{3}$ host. $\mathrm{Tb}^{3+}$ occupies a single type of site in this material. Selection rules permit absorption and emission transitions among different energy levels of terbium ion. Intensity parameters predict emission transitions from ${ }^{5} \mathrm{D}_{3}$ and ${ }^{5} \mathrm{D}_{4}$ levels to several lower manifolds. Hence, the emission spectrum of $\mathrm{LaF}_{3}: \mathrm{Tb}^{3+}$ revealed many more emission peaks (Figure 11) than those observed in $\mathrm{CaF}_{2}: \mathrm{Tb}^{3+}$ (Figure 9). ${ }^{5} \mathrm{D}_{3}$ level emission transitions occur from 380 to $480 \mathrm{~nm}\left({ }^{5} \mathrm{D}_{3}\right.$ to ${ }^{7} \mathrm{~F}_{\mathrm{J}}(\mathrm{J}=6$ to 0$\left.)\right)$. The spectral peaks from 480 to 700 $\mathrm{nm}$ region correspond to ${ }^{5} \mathrm{D}_{4}$ to ${ }^{7} \mathrm{~F}_{\mathrm{J}}(\mathrm{J}=6$ to 0$)$ transitions. Lifetime measurements confirmed these assignments. The lifetime of ${ }^{5} \mathrm{D}_{3}$ level is $1.18 \mathrm{~ms}$ whereas

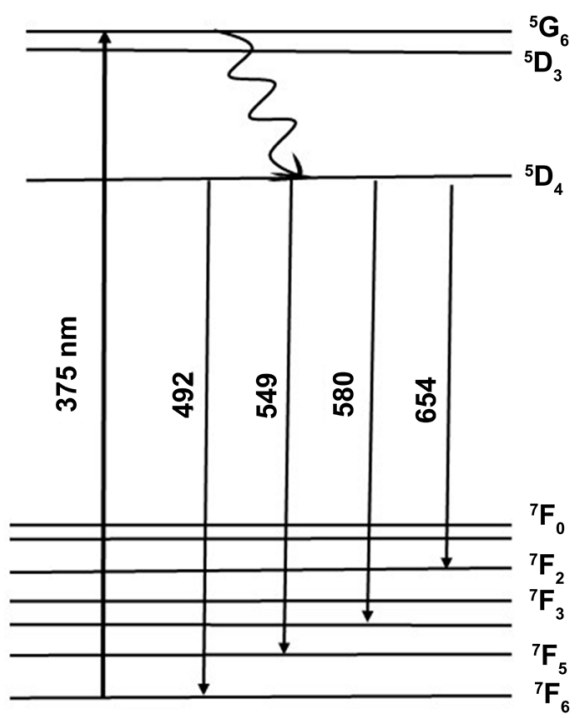

Figure 10. Partial energy level diagram of $\mathrm{Tb}^{3+}$ showing the excitation and emission transitions. 


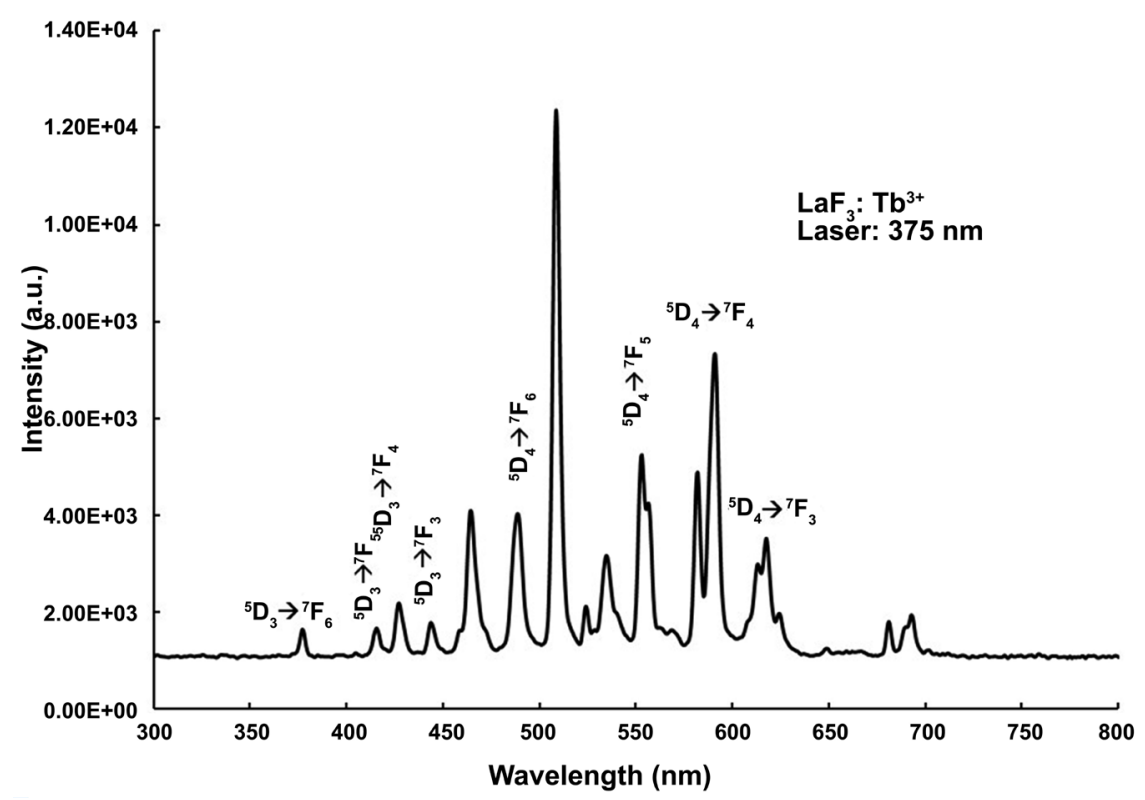

Figure 11. Fluorescence spectrum of $\mathrm{LaF}_{3}: \mathrm{Tb}^{3+}$ induced by $375 \mathrm{~nm}$ laser.

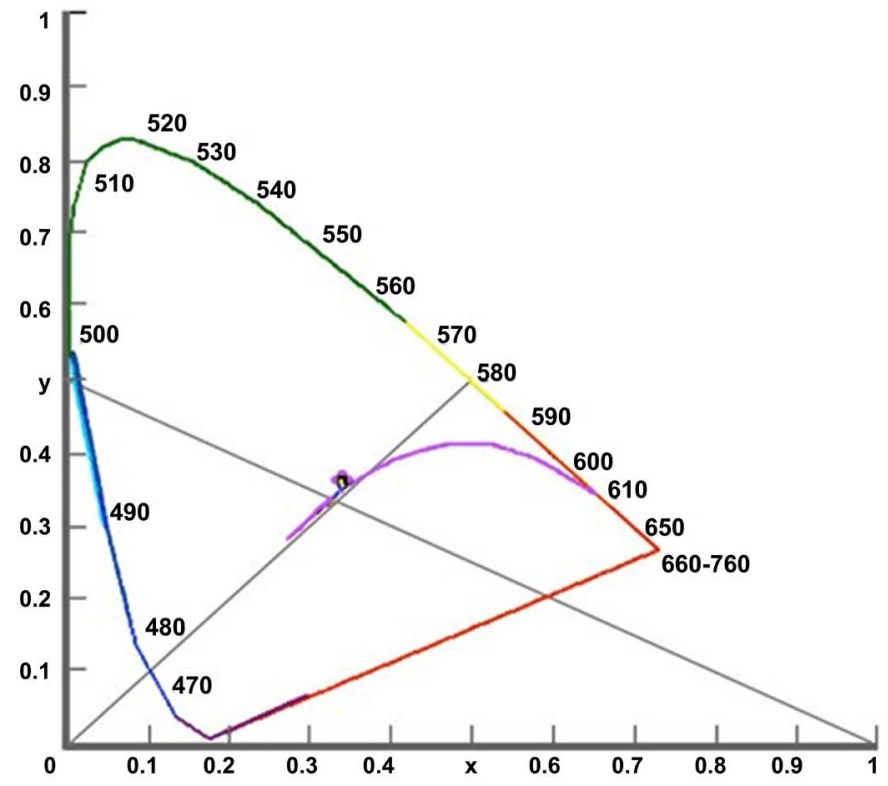

Figure 12. Chromaticity diagram of $\mathrm{LaF}_{3}: \mathrm{Tb}^{3+}$ measured with $375 \mathrm{~nm}$ diode laser excitation. The color coordinates are $\mathrm{x}=0.342$ and $\mathrm{y}=0.365$.

the lifetime of ${ }^{5} \mathrm{D}_{4}$ is longer. Human beings are used to sunlight. How pleasant the sample emission is dependent on the number of spectral wavelengths present in the visible regions. It is customary to characterize the white light in terms of color coordinates. For this purpose, a chromaticity diagram was constructed from the spectral measurements. The color coordinates for $\mathrm{LaF}_{3}: \mathrm{Tb}^{3+}$ are $\mathrm{x}=$ 0.342 and $y=0.365$ (Figure 12). These values are close to those of sunlight values, $\mathrm{x}=0.33$ and $\mathrm{y}=0.33$. It is not surprising because the spectrum of $\mathrm{Tb}^{3+}$-doped $\mathrm{LaF}_{3}$ revealed more peaks in the visible region. The measured coor- 
dinates of $\mathrm{Tb}^{3+}$-doped $\mathrm{CaF}_{2}$ are $\mathrm{x}=0.329$ and $\mathrm{y}=0.558$ (not shown). The $\mathrm{y}$ coordinate deviated from that of sunlight value, $y=0.33$ because of the intense green light emitted by $\mathrm{CaF}_{2}: \mathrm{Tb}^{3+}$ (Figure 9). In a fluoride host the energy gap between the ${ }^{5} \mathrm{D}_{3}$ and ${ }^{5} \mathrm{D}_{4}$ multiplets is approximately $6000 \mathrm{~cm}^{-1}$. Hence, emission occurs from both ${ }^{5} \mathrm{D}_{3}$ and ${ }^{5} \mathrm{D}_{4}$ states to lower manifolds.

\section{Conclusions}

Our studies indicate that the color coordinates of $\mathrm{Dy}^{3+}$-doped $\mathrm{CaF}_{2}, \mathrm{Eu}^{3+}$-doped $\mathrm{LaF}_{3}$ and $\mathrm{Tb}^{3+}$-doped $\mathrm{LaF}_{3}$ are close to that of sunlight and hence these materials are ideal for the development of diode pumped solid state white light emitters. Only low concentrations of the dopant ions are needed as higher concentrations of the dopant will lead to concentration quenching. Though we demonstrated this effect in fluoride single crystals, other low phonon glasses will also work for this purpose. Our investigations indicate that rare-earth ion doped phosphors have potential applications for solid state lighting. Oxyfluoride glasses retain the crystalline emission properties and maintain bulk properties of oxide glasses [29]. Hence, oxide glasses embedded with rare-earth fluoride nanocrystals may exhibit white-light emission.

\section{Acknowledgements}

The research was supported by a grant from the National Science Foundation, Division of Human Resources Development (HRD); Award No. 1546965.

\section{Conflicts of Interest}

The authors declare no conflicts of interest regarding the publication of this paper.

\section{References}

[1] Wallace, J. (2013) Semiconductor Sources: Laser Plus Phosphor Emits White Light without Droop. Laser Focus World, 49, 24-26.

[2] Denault, K.A., Cantore, M., Nakamura, S., Denbaars, S.P. and Seshadri, R. (2013) Efficient and Table Laser Driven White Lighting. AIP Advances, 3, Article ID: 072107. https://doi.org/10.1063/1.4813837

[3] Xie, R.J., Hirosaki, N., Mitomo, M., Takahashi, K. and Sakuma, K. (2006) Highly Efficient White-Light-Emitting Diodes Fabricated with Short-Wavelength Yellow Oxynitride Phosphors. Applied Physics Letters, 88, Article ID: 101104.

[4] Teigerwald, D.A., Bhat, J.C., Collins, D., Fletcher, R.W., Holcomb, M.O., Ludowise, M.J., Martin, P.S. and Rudaz, S.L. (2002) Llimination with Solid State Lighting Technology. IEEE Journal of Selected Topics in Quantum Electronics, 8, 310-320. https://doi.org/10.1109/2944.999186

[5] Allen, S.C. and Stecki, J. (2008) A Nearly Ideal Phosphor-Covered White Light-Emitting Diode. Applied Physics Letters, 92, Article ID: 143309.

[6] Nishiura, S., Tanabe, S., Fujioka, K. and Fujimoto, Y. (2011) Properties of Transparent Ce:YAG Ceramic Phosphors for White LED. Optical Materials, 33, 688-691. https://doi.org/10.1016/j.optmat.2010.06.005 
[7] Kumar, P., Panchakarla, L.S., Bhat, S.V., Maitra, U., Subrahmanaym, K.S. and. Rao, C.N.R. (2010) Photoluminescence, White Light Emittinmg Properties and Related Aspects of ZnO Nanoparticles Admixed with Grapheme and GaN. Nanotechnology, 21, Article ID: 385701. https://doi.org/10.1088/0957-4484/21/38/385701

[8] Nizamoglu, S., Zengin, G. and Demir, H.V. (2008) Color-Converting Combinations of Nanocrystal Emitters for Warm White Light Generation with High Color Rendering Index. Applied Physics Letters, 92, Article ID: 031102.

https://doi.org/10.1063/1.2833693

[9] Masai, H., Fujiwara, T., Matsumoto, S., Takahashi, Y., Awasaki, K., Tojuda, Y. and Yoko, T. (2011) High Efficient White Light Emission of Rare-Earth Free MnO-SnO-ZnO- $\mathrm{P}_{2} \mathrm{O}_{5}$. Journal of the Ceramic Society of Japan, 119, 726-730. https://doi.org/10.2109/jcersj2.119.726

[10] Sivakumar, S., van Veggel, F.C.J.M. and Raudsepp, M. (2005) Bright White Light through Upconversion of a Single NIR Source from Sol-Gel Derived Thin Film Made with $\mathrm{Ln}^{3+}$-Doped $\mathrm{LaF}_{3}$ Nanoparticles. Journal of the American Chemical Society, 127, 12464-12465. https://doi.org/10.1021/ja052583o

[11] Reddy, B.R., Edwards, V.M. and Surabhi, R. (2014) Diode Pumped White Light Emission from Dysprosium and Samrium Doped Glasses. Proceedings SPIE, 8982, 89821D.

[12] Dieke, G.H. (1968) Spectra and Energy Levels of Rare-Earth Ions. Wiley, New York.

[13] Powell, R.C. (1998) Physics of Solid-State Laser Materials. Springer, New York. https://doi.org/10.1007/978-1-4612-0643-9

[14] Epstein, R.I. and Bahe, S. (2009) Optical Refrigeration: Science and Applications of Laser Cooling of Solids. Wiley VCH Verlag GmbH \& Co., Weinham. https://doi.org/10.1002/9783527628049

[15] Reddy, B.R., Kamma, I. and Kommidi, P. (2013) Optical Sensing Techniques for Temperature Measurement. Applied Optics, 52, B33-B39. https://doi.org/10.1364/AO.52.000B33

[16] Reddy, B.R. (2006) Optical Hole Burning Studies in Europium Doped Oxide Glasses. Journal of Non-Crystalline Solids, 352, 483-487.

[17] Carnall, W.T., Crosswhite, H.M. and Crosswhite, H.W. (1978) Energy Level Structure and Ransition Probabilities of the Trivalent Lanthanidesin $\mathrm{LaF}_{3}$. Special Report ANL-78-XX-95, Chemistry Division, Argonne National Laboratory, Argonne.

[18] Moore, D.S. and Wright, J.C. (1981) Laser Spectroscopy of Defect Chemistry in $\mathrm{CaF}_{2}: \mathrm{Er}^{3+}$. The Journal of Chemical Physics, 74, 1626-1636. https://doi.org/10.1063/1.441303

[19] Babu, P., Jang, K.H., Rao, C.S., Shi, L., Jayasankar, C.K., Lavin, V. and Seo, H.J. (2011) White Light Generation in Dy ${ }^{3+}$-Doped Oxyfluoride Glass and Transparent Glass-Ceramics Containing $\mathrm{CaF}_{2}$ Nanocrystals. Optics Express, 19, 1836-1841. https://doi.org/10.1364/OE.19.001836

[20] Reddy, A.A., Das, S., Goel, A., Sen, R., Siegel, R., Mafra, L., Prakash, G.V. and Ferreira, M.F. (2013) $\mathrm{KCa}_{4}(\mathrm{BO} 3) 3: \mathrm{Ln}^{3+}(\mathrm{Ln}=\mathrm{Dy}, \mathrm{Eu}, \mathrm{Tb})$ Phosphors for Near UV Excited White-Light-Emitting Diodes. AIP Advances, 3, Article ID: 022126. https://doi.org/10.1063/1.4794189

[21] Culp, M., Edwards V.M. and Reddy, B.R. (2017) Optical Spectroscopy, Energy Upconversion and White Light Emission Characteristics of $\mathrm{CaF}_{2}: \mathrm{Er}^{3+}$. Journal of Photonics for Energy, 7, Article ID: 026001. https://doi.org/10.1117/1.JPE.7.026001

[22] Reddy, B.R. and Colon, T. (2013) White Light Emission Characteristics of Eu 
Doped Fluoride Crystals. Proceedings SPIE, 8621, 86210 O.

https://doi.org/10.1117/12.2001700

[23] Reddy, B.R., Culp, M., Trivedi, S.B., Hommerich, U. and Brown, E. (2016) White-Light Emission Studies of Dysprosium-Doped Halide Crystals. Proceedings SPIE, 9744, 974406. https://doi.org/10.1117/12.2209405

[24] DiMaio, J.R., Kokuoz, B. and Ballato, J. (2006) White Light Emissions through Down-Conversion of Rare-Earth Doped LaF3 Nanoparticles. Optics Express, 14, 11412-11417. https://doi.org/10.1364/OE.14.011412

[25] Weber, M.J. (1967) Probabilities for Radiative and Nonradiative Decay of $\mathrm{Er}^{3+}$ in $\mathrm{LaF}_{3}$. Physical Review B, 157, 262-272. https://doi.org/10.1103/PhysRev.157.262

[26] Riseberg, R.A. and Moos, H.W. (1967) Multiphonon Orbit-Lattice Relaxation in $\mathrm{LaBr}_{3}, \mathrm{LaCl}_{3}$, and $\mathrm{LaF}_{3}$. Physical Review Letters, 19, 1423-1426. https://doi.org/10.1103/PhysRevLett.19.1423

[27] Forrester, Y.N., Pandher, R.S., Reddy, B.R. and Nash-Stevenson, S.K. (2002) Stepwise Two-Photon Excitation Studies in Terbium-Doped Fluoride Crystals. Optical Materials, 19, 255-258. https://doi.org/10.1016/S0925-3467(01)00187-2

[28] Kommidi, P. and Reddy, B.R. (2007) Two-Photon Excitation Studies in Terbium Doped Yttrium Aluminum Oxide. Journal of Applied Physics, 102, Article ID: 076105. https://doi.org/10.1063/1.2786615

[29] Hashim, H., Konishi, A., Tanigami, Y., Shibata, D. and Kawamoto, Y. (2004) Local Precipitation of Upconversion Nanocrystals in Rare-Earth-Doped Oxyfluoride Glasses by Laser Irradiation. Proceedings SPIE, 5350, 212-221.

https://doi.org/10.1117/12.526202 